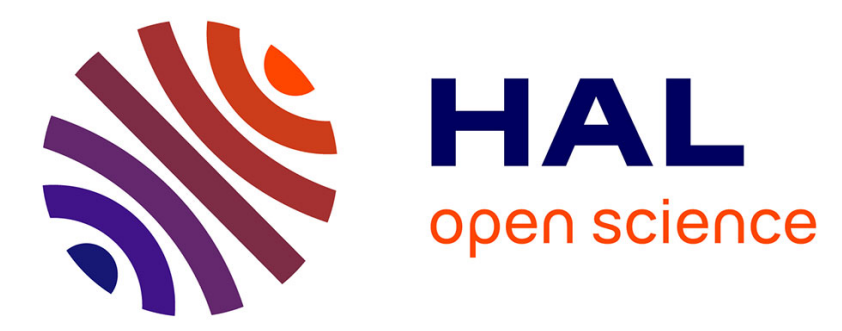

\title{
Contrasting characteristics of sub-microsecond pulsed atmospheric air and atmospheric pressure heliumoxygen glow discharges
}

J L Walsh, D X Liu, F Iza, M Z Rong, M G Kong

\section{- To cite this version:}

J L Walsh, D X Liu, F Iza, M Z Rong, M G Kong. Contrasting characteristics of sub-microsecond pulsed atmospheric air and atmospheric pressure heliumoxygen glow discharges. Journal of Physics D: Applied Physics, 2010, 43 (3), pp.32001. 10.1088/0022-3727/43/3/032001 . hal-00569673

\section{HAL Id: hal-00569673 \\ https://hal.science/hal-00569673}

Submitted on 25 Feb 2011

HAL is a multi-disciplinary open access archive for the deposit and dissemination of scientific research documents, whether they are published or not. The documents may come from teaching and research institutions in France or abroad, or from public or private research centers.
L'archive ouverte pluridisciplinaire HAL, est destinée au dépôt et à la diffusion de documents scientifiques de niveau recherche, publiés ou non, émanant des établissements d'enseignement et de recherche français ou étrangers, des laboratoires publics ou privés. 


\title{
Contrasting characteristics of sub-microsecond pulsed atmospheric air and atmospheric pressure helium- oxygen glow discharges
}

\author{
J. L. Walsh', D. X. Liu' ${ }^{1,2}$, F. Iza ${ }^{1}$, M. Z. Rong ${ }^{2}$, and M. G. Kong ${ }^{1 *}$ \\ ${ }^{1}$ Dept of Electronic and Electrical Engineering, Loughborough University, Leics LE11 3TU, UK \\ ${ }^{2}$ State Key Lab of Electrical Insulation and Power Equipments, Xi'an Jiaotong University, 710049, P. \\ R. China
}

\begin{abstract}
Glow discharges in air are often considered to be the ultimate low-temperature atmospheric pressure plasmas for numerous chamber-free applications. This is due to the ubiquitous presence of air and the perceived abundance of reactive oxygen and nitrogen species in air plasmas. In this paper, sub-microsecond pulsed atmospheric air plasmas are shown to produce a low concentration of excited oxygen atoms but an abundance of excited nitrogen species, UV photons and ozone molecules. This contrasts sharply with efficient production of excited oxygen atoms in comparable helium-oxygen discharges. Relevant reaction chemistry analyzed with a global model suggests that collisional excitation of $\mathrm{O}_{2}$ by helium metastables is significantly more efficient than electron dissociative excitation of $\mathrm{O}_{2}$, electron excitation of $\mathrm{O}$, and ion-ion recombination. These results suggest different practical uses of the two oxygen-containing atmospheric discharges, with air plasmas being well suited for nitrogen and UV based chemistry and $\mathrm{He}-\mathrm{O}_{2}$ plasmas for excited atomic oxygen based chemistry.
\end{abstract}

\footnotetext{
* Author to whom correspondence should be addressed; e-mail: m.g.kong@lboro.ac.uk
} 
Non-equilibrium atmospheric pressure plasmas are becoming increasingly important in industrial and biomedical applications due to the scope and diversity of their reaction chemistry at low gas temperature without the need for a vacuum chamber [1]-[2]. In low pressure discharges, ions tend to be highly energetic hence many low pressure processing applications are driven by ion bombardment, such as semiconductor wafer processing [3]. At atmospheric pressures, where collisions occur on a picosecond timescale and the mean free path is on a tens of nanometers scale, it is difficult to accelerate ions to the energies required to trigger ion-enabled surface chemistry [4]. Consequently, applications employing atmospheric plasmas tend to be driven by a high flux of reactive chemical species such as atomic $\mathrm{O}, \mathrm{O}_{3}, \mathrm{OH}, \mathrm{NO}$, and others [2][5][7]. Detailed understanding of reaction chemistry in atmospheric discharges is essential to achieve optimum application efficacy and processing control. The need to maximize the flux of reactive species produced must be balanced out by the need to maintain plasma stability. This is challenging for atmospheric plasmas and is often approached by employing a noble base gas (e.g. helium or argon) mixed with a small admixture of a reactive precursor gas such as oxygen [5]-[8]. For practical applications where process economy is important, it is always attractive to use less costly molecular gases, for example air. The usual tendency for atmospheric air discharges to evolve into a hot filamentary plasma can be controlled effectively by using, for example, sub-microsecond pulsed excitation [9]-[11] and micrometer-scale discharge geometry [12][13].

While it is possible to generate stable and low-temperature atmospheric air plasmas, it is not clear whether they offer appropriate reaction chemistry. This study compares the production of key reactive species and UV photons in two oxygen-containing atmospheric plasmas, namely a pulsed helium-oxygen discharge and a pulsed air discharge. In all experiments detailed here, the electrode unit consisted of two cylindrical steel electrodes with a $2 \mathrm{~mm}$ separation, the electrode area was $7 \mathrm{~cm}^{2}$ and a $1 \mathrm{~mm}$ thick $\mathrm{Al}_{2} \mathrm{O}_{3}$ sheet covered one electrode thus reducing the gas gap to $1 \mathrm{~mm}$. The electrode unit was housed in an 
enclosure into which air was fed at a rate of 5 standard liters per minute (SLM). In the $\mathrm{He}-\mathrm{O}_{2}$ case, the total gas flow was fixed at 5SLM with an adjustable $\mathrm{O}_{2} / \mathrm{He}$ ratio nominally at $0.5 \%$ that was found to achieve an optimal inactivation of bacteria [14] and biomolecules [5]. A home-made high voltage pulse generator delivered pulses up to $15 \mathrm{kV}$ in magnitude and 200ns FWHM duration to the dielectric covered electrode at $5 \mathrm{kHz}$. The average dissipated power was calculated by integrating the instantaneous power over a single pulse and multiplying by the repetition frequency. This was done in real-time allowing the power dissipation in the plasma to be monitored in-situ. A fiber optic cable and collimating lens were fixed $5 \mathrm{~mm}$ from the discharge edge to allow optical diagnostics to be conducted. To support the experimental study, a global model of $\mathrm{He}-\mathrm{O}_{2}$ plasmas was developed. Similar global models have been widely used for analyzing capacitively-coupled discharges both at low and atmospheric pressure [15][16]. As global models are computationally simple, it is possible to implement large number of reactions and species to realistically model complex discharge chemistry. The global model employed here accounts for 18 species, including $e$, $\mathrm{He}^{*}, \mathrm{He}_{2}{ }^{*}, \mathrm{He}^{+}, \mathrm{He}_{2}{ }^{+}, \mathrm{O}\left({ }^{1} \mathrm{D}\right), \mathrm{O}\left({ }^{1} \mathrm{~S}\right), \mathrm{O}, \mathrm{O}_{2}(\mathrm{a}), \mathrm{O}_{2}(\mathrm{~b}), \mathrm{O}^{+}, \mathrm{O}_{2}{ }^{+}, \mathrm{O}^{-}, \mathrm{O}_{2}{ }^{-}, \mathrm{O}_{3}$, and $\mathrm{O}_{3}{ }^{-}$, contributing to 206 reactions. The input parameters are dissipated power, gas temperature and densities of ground state $\mathrm{He}$ and $\mathrm{O}_{2}$. For a given power, the particle and power balance equations are solved simultaneously to determine the steady-state plasma composition [15].

Using the 200 ns voltage pulses with rise and fall time of $<20$ ns, both pulsed atmospheric discharges were found to be stable and free from streamers. Figure 1 depicts their measured current and voltage waveforms with $\mathrm{O}_{2} / \mathrm{He}=0.5 \%$ for the $\mathrm{He}-\mathrm{O}_{2}$ plasma. While the temporal characters of their electrical signals are similar, the peak voltage of the air plasma is higher at $5.9 \mathrm{kV}$ than $4 \mathrm{kV}$ of the $\mathrm{He}-\mathrm{O}_{2}$ plasma. Its currents are also larger at $15 \mathrm{~A}$ and $-14 \mathrm{~A}$ associated with the rising and falling edges of the voltage, respectively, compared to $12.6 \mathrm{~A}$ and $10 \mathrm{~A}$ in the $\mathrm{He}-\mathrm{O}_{2}$ plasma. These would suggest a more intense discharge in the air plasma. However, the average dissipated power in both discharges was 
found to be very similar at $\sim 3 W$. Further analysis uncovered that the $\mathrm{He}-\mathrm{O}_{2}$ plasma consumed $65 \%$ of the total power dissipated during the 200 ns pulse duration with the remaining $35 \%$ occurring at the voltage rising and falling edges. In contrast, only $10 \%$ of the power in the air discharge was dissipated during the voltage pulse of 200 ns. Close inspection of figure 1 a reveals a DC current component of $\sim 2 A$ throughout the duration of the voltage pulse. This DC current may be related to the drift of electrons generated via Penning ionization of nitrogen impurity $\left(\varepsilon_{\mathrm{iz}} \sim 15 \mathrm{eV}\right)$ in the helium gas by atomic and molecular helium metastables, $\left(\mathrm{He}\left(2^{3} \mathrm{~S}\right) 19.8 \mathrm{eV}, \mathrm{He}\left(2^{1} \mathrm{~S}\right) 20.6 \mathrm{eV}\right.$, and $\left.\mathrm{He}_{2}{ }^{*} 18.4 \mathrm{eV}\right)$ [17]. These helium species are obviously absent in the air discharge, whereas other metastables such as nitrogen and oxygen do not have sufficient energy to ionize the background gas, $O\left({ }^{1} \mathrm{D}\right)$ 1.97eV, $\left.\mathrm{O}_{2}{ }^{*}{ }^{1} \Delta_{\mathrm{g}}\right) 0.98 \mathrm{eV}, \mathrm{N}_{2}\left(\mathrm{~A}^{3} \Sigma_{\mathrm{u}}^{+}\right) 6.22 \mathrm{eV}$, and $\mathrm{N}_{2}\left(\mathrm{C}^{3} \Pi_{\mathrm{u}}\right) 11.05 \mathrm{eV}[18]$.

The relative emission spectra of the UV band (250-400nm) shown in figures $2 \mathrm{a}$ and $2 \mathrm{c}$ were obtained using a 1200 grooves $/ \mathrm{mm}$ grating to give a spectral resolution of $\sim 0.1 \mathrm{~nm}$. The absolute emission spectra of the visible spectrum $(400-850 \mathrm{~nm})$ in figures $2 \mathrm{~b}$ and $2 \mathrm{~d}$ were measured with a 150 grooves/mm grating that provided a $\sim 2 \mathrm{~nm}$ resolution. Emission spectra from the He- $\mathrm{O}_{2}$ discharge are dominated by excited atomic oxygen, $\mathrm{O}\left({ }^{5} \mathrm{P}\right)$ and $\mathrm{O}\left({ }^{3} \mathrm{P}\right)$ at $777 \mathrm{~nm}$ and $845 \mathrm{~nm}$ respectively. Helium, nitrogen and $\mathrm{OH}$ species are also observed but at a lower intensity. Emission from the $2^{\text {nd }}$ positive system of $\mathrm{N}_{2}$ is significantly lower than $\mathrm{N}_{2}{ }^{+}\left(\mathrm{B}_{2} \Sigma_{\mathrm{g}}{ }^{+}\right)$emission at $391 \mathrm{~nm} \cdot \mathrm{N}_{2}{ }^{+}\left(\mathrm{B}_{2} \Sigma_{\mathrm{g}}{ }^{+}\right)$is readily produced through, among other routes, Penning ionization by helium metastables [17][19][20]. This supports the explanation for the DC current in figure $1 \mathrm{a}$ that it is likely due to electrons produced via Penning processes. Despite the far higher concentration of $\mathrm{He}$ than $\mathrm{O}_{2}$ in the background gas, He emission at $706 \mathrm{~nm}\left({ }^{3} \mathrm{~S}_{1}{ }^{-} \mathrm{P}_{1}\right)$ is significantly lower than atomic oxygen emission at 777 and $845 \mathrm{~nm}$. This has been reported in other atmospheric helium discharges [17][20]-[22], and is attributed to different excitation mechanisms [20]. 
For the air plasma, there is strong emission from nitrogen species below $400 \mathrm{~nm}$, most notably the nitrogen second positive system but also from nitric oxide. In comparison to the He- $\mathrm{O}_{2}$ discharge, the $\mathrm{N}_{2}$ second positive emission of the air plasma is notably larger and $\mathrm{OH}$ emission is absent. High nitrogen emission in the air plasma is likely due to the far greater $\mathrm{N}_{2}$ concentration than in the He- $\mathrm{O}_{2}$ mixture. However $\mathrm{N}_{2}{ }^{+}\left(\mathrm{B}^{2} \Sigma_{\mathrm{g}}{ }^{+}\right)$emission is comparable in the two discharges. In a $\mathrm{He}-\mathrm{O}_{2}$ plasma with a small $\mathrm{N}_{2}$ density as impurity, Penning reactions involving He metastables contribute significantly to $\mathrm{N}_{2}{ }^{+}\left(\mathrm{B}^{2} \Sigma_{\mathrm{g}}{ }^{+}\right)$emission and are likely to account for comparable $391 \mathrm{~nm}$ emission in the two plasmas. The most striking difference in figure 2 is that the air plasma produces very little emission above $400 \mathrm{~nm}$ where many reactive oxygen emission lines exist. In particular, there is little emission at the atomic oxygen lines of $777 \mathrm{~nm}$ and $845 \mathrm{~nm}$. This contrast in excited atomic oxygen is significant for bacterial and biomolecule inactivation [5][23] and will be discussed further with simulation data.

Gas temperature has direct implications for many applications and influences plasma chemistry. The contrast in excited atomic oxygen of the two oxygen-containing plasmas indicated in figure 2 may be influenced by a difference in their gas temperature. Molecular gas discharges, especially in air, are known to have elevated temperatures when compared to noble gas discharges in helium and argon. Typically, this is because air discharges require substantially higher power densities than noble gas discharges particularly when driven by continuous-wave excitation. The effect of short-pulsed excitation, however, acts to reduce the amount of power needed to sustain the discharge [24], and its long off-time allows significant gas cooling between consecutive pulses leading to a lower gas temperature. As a result, the average dissipated power densities in sub-microsecond pulsed discharges are considerably reduced to $2 \sim 10 \mathrm{~W} / \mathrm{cm}^{3}$ regardless of the gas used [10][21]. Figure 3 highlights the rotational temperature of nitrogen at a constant dissipated power of $3 \mathrm{~W}$ in the two discharges, obtained from Specair assuming that nitrogen rotational and translational 
temperatures are in equilibrium. Figure $3 \mathrm{a}$ and $3 \mathrm{~b}$ suggest that $T_{\text {rot }}=310 \mathrm{~K}$ in the $\mathrm{He}-\mathrm{O}_{2}$ discharge and $T_{\text {rot }}=330 \mathrm{~K}$ in the air discharge. As expected, the air discharge has a slightly higher gas temperature, however the fitting errors are found to be up to $\pm 10 \mathrm{~K}$. Consequently the gas temperature in both discharges can be considered to be similar and is unlikely to contribute to the contrast in excited $\mathrm{O}$ emission. Figure $3 \mathrm{c}$ shows that $T_{\text {rot }}$ of the He- $\mathrm{O}_{2}$ plasma changes from $300 \mathrm{~K}$ to $340 \mathrm{~K}$ between $1 \mathrm{~W}$ to $6 \mathrm{~W}$, whereas the temperature in the air plasma increases from $330 \mathrm{~K}$ to $350 \mathrm{~K}$ when power is increased from $2 \mathrm{~W}$ to $6 \mathrm{~W}$. The rate of change of temperature is greater in the $\mathrm{He}-\mathrm{O}_{2}$ plasma, and this is attributed to the heating by the DC current component during the voltage pulse.

Figures $4 a$ and $4 b$ show the excited oxygen emission intensity and ozone concentration from each discharge as a function of input power. Figure 4a shows the trend in emission intensity of atomic oxygen, $\mathrm{O}\left({ }^{5} \mathrm{P}\right)$ at $777 \mathrm{~nm}$ and $\mathrm{O}\left({ }^{3} \mathrm{P}\right)$ at $845 \mathrm{~nm}$, for both the air and heliumoxygen discharges. At $3 \mathrm{~W}$, emission intensity of excited atomic oxygen in the $\mathrm{He}-\mathrm{O}_{2}$ plasma is a factor of 85 and 180 at $777 \mathrm{~nm}$ and $845 \mathrm{~nm}$, respectively, higher than in the air plasma. An increase in dissipated power yields an increase in emission intensity of both species, as a higher dissipated power yields a higher electron density which in turn produces a higher density of species. For ozone concentration shown in figure $4 b$, each measurement was taken 20s after igniting the discharge, a Gastec ozone sampling tube (18M 2-200ppm range) was placed at the exhaust of the discharge chamber and a sample was drawn from the exhaust gas. As ozone takes a significant time to decompose back to oxygen, it was necessary to flush the enclosure with the base gas for several minutes after each measurement was taken to remove any residual ozone. Similar to the $\mathrm{O}$ trend in figure $4 \mathrm{a}$, ozone production is proportional to the dissipated power. In the air plasma, ozone levels increase from $70 \mathrm{ppm}$ at $2 \mathrm{~W}$ to $170 \mathrm{ppm}$ at $6 \mathrm{~W}$, comparable to those reported in similar atmospheric discharges [25]. In the $\mathrm{He}^{-} \mathrm{O}_{2}$ plasma, the ozone density increases from $15 \mathrm{ppm}$ at $1 \mathrm{~W}$ to $95 \mathrm{ppm}$ at $6 \mathrm{~W}$ when $\mathrm{O}_{2} / \mathrm{He}=0.5 \%$. Also shown is the ozone concentration for 
$\mathrm{O}_{2} / \mathrm{He}=1 \%$ and $1.5 \%$ at a constant power of $6 \mathrm{~W}$, suggesting an ozone increase by roughly $50 \mathrm{ppm}$ for every $0.5 \%$ of oxygen added to the base gas.

To help with the interpretation of figure 4 , key reactions in the two $\mathrm{O}_{2}$-containing plasmas are analyzed. For the air plasma, air is assumed to consist of only $\mathrm{N}_{2}$ and $\mathrm{O}_{2}$ as impurities such as $\mathrm{Ar}, \mathrm{CO}_{2}$ and water vapor were absent from figure 2. Table 1 highlights the main pathways responsible for $\mathrm{O}\left({ }^{3} \mathrm{P}\right)$ and $\mathrm{O}\left({ }^{5} \mathrm{P}\right)$ population and depopulation in a $\mathrm{He}-\mathrm{O}_{2}$ discharge, and figure 5 shows relative contributions of these mechanisms calculated from the $\mathrm{He}+\mathrm{O}_{2}$ global model. The steady-state electron temperature is found to be $\sim 2.5 \mathrm{eV}$. Pathways 1 and 2 (table 1 ) involve electron excitation of $\mathrm{O}_{2}$ and $\mathrm{O}$ respectively. While the rate coefficient in pathway 2 is $\sim 100$ times higher than that in pathway 1 , the density ratio of $[\mathrm{O}] /\left[\mathrm{O}_{2}\right]$ is approximately $10^{-3}$ meaning pathway 1 dominates over pathway 2 [26]. Collisional excitation by He metastables is found to be extremely efficient for $O\left({ }^{3} \mathrm{P}\right)$ and $O\left({ }^{5} \mathrm{P}\right)$ production. This is in spite of rate coefficients for collisional excitation to $\mathrm{O}\left({ }^{3} \mathrm{P}\right)$ and $\mathrm{O}\left({ }^{5} \mathrm{P}\right)$ by helium metastables being estimated conservatively at $10^{-12} \mathrm{~cm}^{3} / \mathrm{s}$ here, based on the reported total rate for $\mathrm{He}^{*}+\mathrm{O}_{2}$ of $2.4 \times 10^{-10} \mathrm{~cm}^{3} / \mathrm{s}$ [27]. As reported previously [20], oxygen emission in the presence of nitrogen is not time modulated, suggesting that electron excitation reactions are unlikely to be significant in the population of $O\left({ }^{3} \mathrm{P}\right)$ and $\mathrm{O}\left({ }^{5} \mathrm{P}\right)$. Ion-ion recombination is another possible population pathway. Simulation results indicate that $\mathrm{O}_{2}^{+}$is the dominant ion while $\mathrm{O}^{-}$and $\mathrm{O}_{2}^{-}$are the dominant anions. Their recombination rates are about three orders of magnitude higher than for pathway 3 , however the density ratio of ${\mathrm{O}^{-}}^{-}$ $\left.+\mathrm{O}_{2}^{-}\right] /\left[\mathrm{O}_{2}\right]$ is $10^{-6}$. As a result, ion-ion recombination is not an efficient population mechanism of $\mathrm{O}\left({ }^{3} \mathrm{P}\right)$ and $\mathrm{O}\left({ }^{5} \mathrm{P}\right)$. Depopulation of $\mathrm{O}\left({ }^{3} \mathrm{P}\right)$ and $\mathrm{O}\left({ }^{5} \mathrm{P}\right)$ occurs via radiation (pathway 5$)$ and quenching (pathway 6). The quenching rate is found to be $2.88 \times 10^{8} \mathrm{~s}^{-1}$, and the rate ratio from quenching to radiation is 9:1. Radiative processes, however, are still significant.

In the atmospheric air discharge, similar population processes are expected [18] except for those involving helium metastables (e.g. pathway 3). Other metastable states, such as 
nitrogen, do not have sufficient energy to cause collisional excitation of oxygen. In addition, electron excitation of $\mathrm{O}_{2}$ and $\mathrm{O}$ are expected to be inefficient due to the electronegative nature (i.e. low electron density) at low temperature $(<1000 \mathrm{~K})$ air plasmas [18]. Ion-ion recombination is also inefficient in air discharges at low-temperature $(<1000 \mathrm{~K})$ due to the very low density of $\mathrm{O}_{2}^{+}[18]$. On the other hand, the main depopulation process of $\mathrm{O}\left({ }^{3} \mathrm{P}\right)$ and $\mathrm{O}\left({ }^{5} \mathrm{P}\right)$ in the air plasma is quenching with $\mathrm{N}_{2}$ and $\mathrm{O}_{2}$. Ref [32] suggests that the quenching rate coefficient via nitrogen is $4.2 \times 10^{-10} \mathrm{~cm}^{-3} \mathrm{~s}^{-1}$, leading to a quenching rate of $1.31 \times 10^{10} \mathrm{~s}^{-1}$ in the air plasma. This indicates a rate ratio from quenching to radiation is about $400: 1$ in the air plasma, so radiative decay contributes far less to the depopulation rate. In comparison with the $\mathrm{He}-\mathrm{O}_{2}$ plasma, the depopulation of excited atomic oxygen is about $\sim 45$ times greater in the air plasma. In short, population of $\mathrm{O}\left({ }^{3} \mathrm{P}\right)$ and $\mathrm{O}\left({ }^{5} \mathrm{P}\right)$ in a $\mathrm{He}+\mathrm{O}_{2}$ discharge is significantly more efficient than in an air discharge and its quenching is significantly slower. As a result very little atomic oxygen emission is observed in air discharges when compared with $\mathrm{He}+\mathrm{O}_{2}$ plasmas.

For atmospheric pressure discharges particularly in molecular gases, short-pulse excitation is critical to attain low gas temperature and robust plasma stability compared to the common sinusoidal excitation [25][32][33]. In general, the extent of these benefits depends on pulsewidth [21][34]-[36], pulse rise and fall times [34][37], and pulse repetition frequency [21][34][38]. Similar to most high-pressure short-pulsed plasmas, the submicrosecond pulsed atmospheric plasmas reported here employ a dielectric-barrier configuration and the use of dielectric barriers results in typically two current pulses for every voltage pulse (see figure 1). Typically, discharge current is observed during the voltage rising and falling phases with very little current flow during the applied voltage. When the pulsewidth of the applied voltage was increased from 200 ns in the case of figure $1-4$, the two current pulses produced during one voltage pulse were moved further apart by the increased pulsewidth of the applied voltage. With the averaged dissipated power 
maintained at $3 \mathrm{~W}$, the gas temperature was relatively independent of the voltage pulsewidth in our experiments. For example at a voltage pulse of $1 \mu$ s and a dissipated power of 3W, the gas temperature was found to be $340 \mathrm{~K}$ and $330 \mathrm{~K}$ for the pulsed atmospheric air and atmospheric $\mathrm{He}-\mathrm{O}_{2}$ plasmas, respectively. With an error bar of $\pm 10 \mathrm{~K}$, these are similar to $330 \mathrm{~K}$ and $310 \mathrm{~K}$ for the air and $\mathrm{He}-\mathrm{O}_{2}$ plasmas, respectively, when the voltage pulsewidth was 200ns (see figure 3). The larger temperature increase in the $\mathrm{He}-\mathrm{O}_{2}$ case is due to the small dc component in its discharge current (see figure 1a). It should be emphasized however that in the $\mathrm{He}-\mathrm{O}_{2}$ case both the applied voltage and the discharge current had to be reduced considerably to maintain the same averaged dissipated power of $3 \mathrm{~W}$ when the voltage pulsewidth was increased to $1 \mu \mathrm{s}$ from 200ns. If the applied voltage is allowed to increase, the averaged dissipated power would increase and the gas temperature would also increase. For our experiments, the benefits of pulsed excitation in terms of low gas temperature and large reactive species concentrations would start to diminish after the voltage pulsewidth is much above $100 \mu \mathrm{s}$ and the rise time above $10 \mu \mathrm{s}$. This suggests an interesting correlation between the gas temperature and the averaged dissipated power in two different gases.

More importantly however is that shorter pulsewidth allows for the use of much elevated applied voltage (hence larger reduced electric field of $E / M$ ) to induce greater peak discharge current (hence higher electron density), both desirable for active plasma chemistry. In fact, the use of sub-microsecond and even nanosecond pulsed excitation would facilitate the possibility to manipulate the electron energy distribution function and in turn manipulate plasma chemistry [37]. This study has not addressed directly the effect of pulse risetime and pulse repetition frequency. However it is known that shorter risetime would permit the use of over-voltage and the resulting increase in E/N would lead to more abundant reactive species and UV emission [34]. It is also known that higher repetition frequency would in general increase the production of reactive plasma species [21] though 
the relationship is not always monotonic [38]. It is important to remark that the use of short pulses not only reduces the gas temperature but also enables access to active and diverse plasma chemistry that cannot be easily accessed using sinusoidal excitation. Finally it is worth mentioning that sub-microsecond pulsed atmospheric plasmas were achieved in helium without dielectric barriers with one current pulse every voltage pulse [21][37][39], suggesting a different plasma generation mechanism.

In conclusion, this paper has presented a study of two atmospheric oxygen-containing discharges. Using sub-microsecond pulses, the gas temperature was low and similar in both cases. Of particular note is that atomic oxygen emission intensity was about two orders of magnitude higher in the $\mathrm{He}-\mathrm{O}_{2}$ discharge compared to that observed in the air plasma. A global model for $\mathrm{He}-\mathrm{O}_{2}$ plasmas was used to establish that production of excited oxygen atoms is more efficient in the $\mathrm{He}-\mathrm{O}_{2}$ plasma than in the air plasma. Furthermore, quenching of $\mathrm{O}\left({ }^{3} \mathrm{P}\right)$ and $\mathrm{O}\left({ }^{5} \mathrm{P}\right)$ in the air plasma were found to be $\sim 45$ times greater than in the $\mathrm{He}-\mathrm{O}_{2}$ discharge. These two findings explain the contrast in excited $\mathrm{O}$ emission and suggest that the two oxygen-containing atmospheric discharges may have different uses, with air plasmas being well suited for applications requiring nitrogen and UV based chemistry and $\mathrm{He}-\mathrm{O}_{2}$ plasmas for those requiring excited atomic oxygen. 


\section{References:}

[1] Iza F, Kim GJ, Lee SM, Lee JK, Walsh JL, Zhang YT and Kong MG 2008 Plasma Processes Polym 5, 322.

[2] Fridman G, Friedman G, Gutsol A, Shekhter AB, Vasilets VN and Fridman A 2008 Plasma Processes Polym 503.

[3] Graves DB 1994 IEEE Trans. Plasma Sci. 2231.

[4] Iza F, Lee JK and Kong MG, 2007 Phys. Rev. Lett. 99, 075004.

[5] Deng XT, Shi JJ and Kong MG 2007 J. Appl. Phys. 101, 074701.

[6] Walsh JW and Kong MG 2008 Appl. Phys Lett. 93, 111501.

[7] Shimizu T, Steffes B, Pompl R, Jamitzky F, Bunk W, Ramrath K, Georgi M, Stolz W, Schmidt HU, Urayama T, Fujii S and Morfill GE 2008, Plasma Processes and Polymers 557.

[8] Walsh JW and Kong MG 2008 Appl. Phys Lett. 91, 221502.

[9] Pancheshnyi SV, Lacoste DA, Bourdon A and Laux CO 2006 IEEE Trans. Plasma Sci 342478.

[10] Walsh JL and Kong MG 2007 Appl. Phys. Lett. 91, 251504.

[11] Ayan H, Staack D, Fridman G, Gutsol A, Mukhin Y, Starikovskii A, Fridman A and Friedman G 2007, J Phys D Appl Phys 42, 125202.

[12] Hopwood J and Iza F 2004, J. Anal. at. Spectrom. 19, 1145.

[13] Kolb JF, Mohamed AH, Price RO, Swanson RJ, Bowman A, Chiavarini RL, Stacey M and Schoenbach KH 2008, Appl. Phys. Lett. 92, 241501.

[14] Yu H, Perni S, Shi JJ, Wang DZ, Kong MG and Shama G 2006 J. Appl. Microbiology, 101, 1323.

[15] Kim S, Lieberman MA, Lichtenberg AJ and Gudmundsson JT 2006 J Vac Sci Technol A 242025.

[16] Stalder KR, Vidmar RJ, Nersisyan G and Graham WG 2006 J Appl Phys 99, 093301.

[17] Nersisyan G, Morrow T and Graham WG 2004, Appl. Phys. Lett. 85, 1487.

[18] Becker KH, Kogelschatz U, Schoenbach KH, and Baker RJ, "Non-equilibrium air plasmas at atmospheric pressure", loP Publishing, ISBN 0750309628 (2005).

[19] Sublet A, Ding C, Dorier J, Hollenstein C, Fayet P and Coursimault F, 2006 Plasma Sources Sci Technol 15, 627.

[20] Liu DW, Iza F and Kong MG 2009 Appl Phys Lett 95, 031501.

[21] Walsh JL and Kong MG 2006 Appl. Phys. Lett. 89, 231503.

[22] Niemi K, Schulz-von der Gathen V and Doebele HF 2001 J Phys D: Appl Phys 34, 2330.

[23] Perni S, Shama G, Hobman JL, Lund PA, Kershaw CJ, Hidalgo-Arroyo GA, Penn CW, Deng XT, Walsh JL and Kong MG 2007 Appl. Phys. Lett. 90, 073902.

[24] Walsh JL, Shi JJ and Kong MG 2006 Appl. Phys. Lett. 88, 171501.

[25] Williamson JM, Thump DD, Bletzinger P and Ganguly BN, 2006 J Phys D: Appl Phys 39, 4400.

[26] Pagnon D, Amorim J, Nahorny J, Touzeau M and Vialle M 1995 J Phys D: Appl Phys 28, 1856.

[27] Leveille V and Coulombe S 2006 Plasma Process Polym 3, 587.

[28] Ishikawa T, Hayashi D, Sasaki K and Kadota K 1998 Appl. Phys. Lett. 72, 2391.

[29] Zhou XX and Dickson AS 1997 Nuclear Instrum Method Phys Res B, 124, 51.

[30] Ralchenko Yu, Kramida AE, Reader J and NIST ASD Team (2008). NIST Atomic Spectra Database (version 3.1.5) 
[31] Gordiets BF, Ferreira CM, Guerra VL, Loureiro JMA, Nahorny J, Pagnon D, Touzeau M and Vialle M 1995 IEEE Tran Plasma Sci 23, 750

[32] Mildren RP and Carman RJ 2001 J Phys D: Appl Phys 34, L1.

[33] Kong MG and Deng XT 2003 IEEE Trans. Plasma Sci 317.

[34] Leiweke RJ and Ganguly BN 2007 Appl. Phys. Lett. 90, 241501.

[35] Lu X, Xiong Q, Xiong Z, Xian Y, Zhou F, Hu J, Gong W, Zhou C, Tang Z, Jiang Z and Pan Y 2009 IEEE Trans. Plasma Sci 37647.

[36] Panousis E, Merbahi N, Clément F, Ricard A, Yousfi M, Papageorghiou L, Loiseau JF, Eichwald O, Held B and Spyrou N 2009 IEEE Trans. Plasma Sci 371004.

[37] Iza F, Walsh JW and Kong MG 2008 IEEE Trans. Plasma Sci 371289.

[38] Carman RJ, Mildren RP, Ward BK and Kane DM 2004 J Phys D: Appl Phys 37, 2399.

[39] Walsh JW and Kong MG 2006 Appl. Phys. Lett. 89, 161505. 


\section{Figure Caption:}

Figure 1: $\quad$ Current and voltage waveforms obtained in the pulsed atmospheric dielectric barrier discharge operating in (a) helium with $0.5 \%$ oxygen admixture and (b) ambient air.

Figure 2: $\quad$ Relative (a) and absolute (b) emission spectra of the pulsed $\mathrm{He}+\mathrm{O}_{2}$ plasma at $\mathrm{O}_{2} / \mathrm{He}=0.5 \%$, and relative (c) and absolute (d) emission spectra of the pulsed air discharge, both operating at $3 \mathrm{~W}$

Figure 3: $\quad$ Experimental and simulated best-fit data of the second positive nitrogen emission band for (a) the $\mathrm{He}-\mathrm{O}_{2}$ plasma, and (b) the air plasma, both at $3 \mathrm{~W}$ of dissipated power, with the power dependence of the rotational temperature in (c).

Figure 4: $\quad$ Dissipated power dependence of (a) the absolute emission intensity of $O\left({ }^{5} \mathrm{P}\right)$ at $777 \mathrm{~nm}$ and $\mathrm{O}\left({ }^{3} \mathrm{P}\right)$ at $845 \mathrm{~nm}$ and (b) ozone concentration for the air and the $\mathrm{He}-\mathrm{O}_{2}$ plasma. In the $\mathrm{He}^{-} \mathrm{O}_{2}$ plasma, $\mathrm{O}_{2} / \mathrm{He}$ is (a) $0.5 \%$ and (b) $0.5,1.0$ and $1.5 \%$.

Figure 5: $\quad$ Schematic representation of the $\mathrm{He}-\mathrm{O}_{2}$ global model results showing key reaction pathways responsible for populating and depopulating (a) $\mathrm{O}\left({ }^{3} \mathrm{P}\right)$ and (b) $\mathrm{O}\left({ }^{5} \mathrm{P}\right)$ at $6 \mathrm{~W}$ of dissipated power. Percentages indicate their relative contributions.

Table 1: $\quad$ Key reactions and their rate coefficients used in the $\mathrm{He}-\mathrm{O}_{2}$ global model 


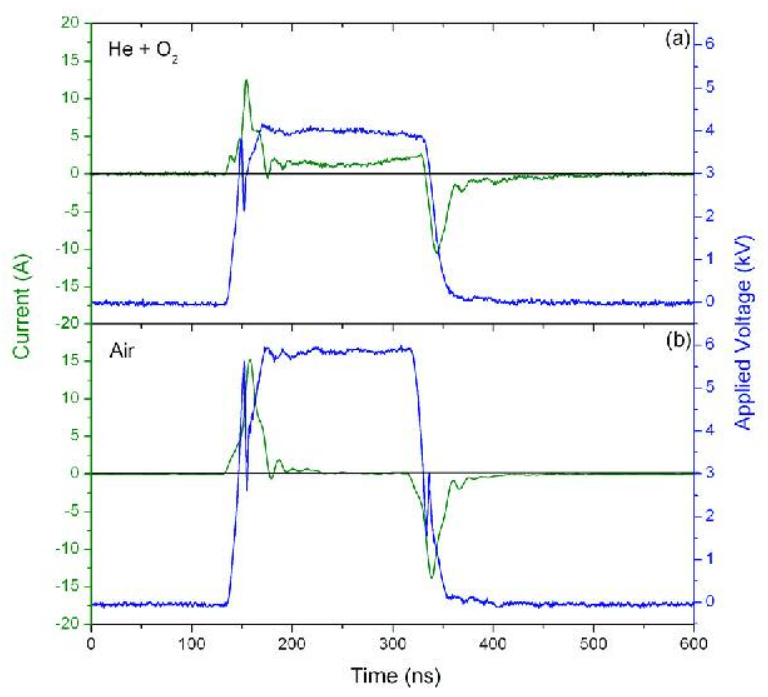

Figure 1: $\quad$ Current and voltage waveforms obtained in the pulsed atmospheric dielectric barrier discharge operating in (a) helium with $0.5 \%$ oxygen admixture and (b) ambient air. 


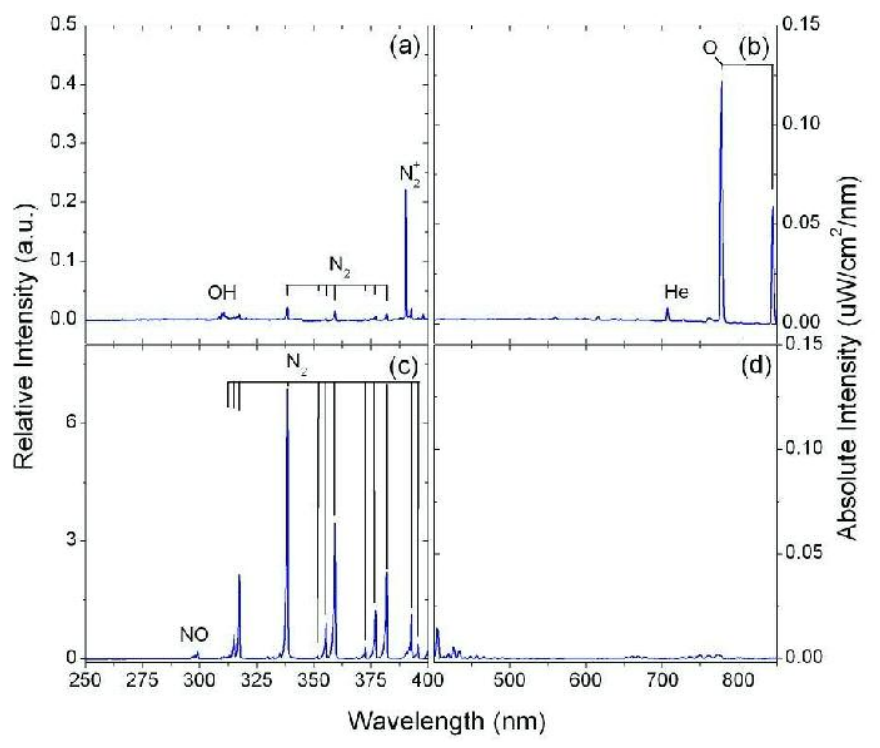

Figure 2: $\quad$ Relative (a) and absolute (b) emission spectra of the pulsed $\mathrm{He}+\mathrm{O}_{2}$ plasma at $\mathrm{O}_{2} / \mathrm{He}=0.5 \%$, and relative (c) and absolute (d) emission spectra of the pulsed air discharge, both operating at $3 \mathrm{~W}$. 


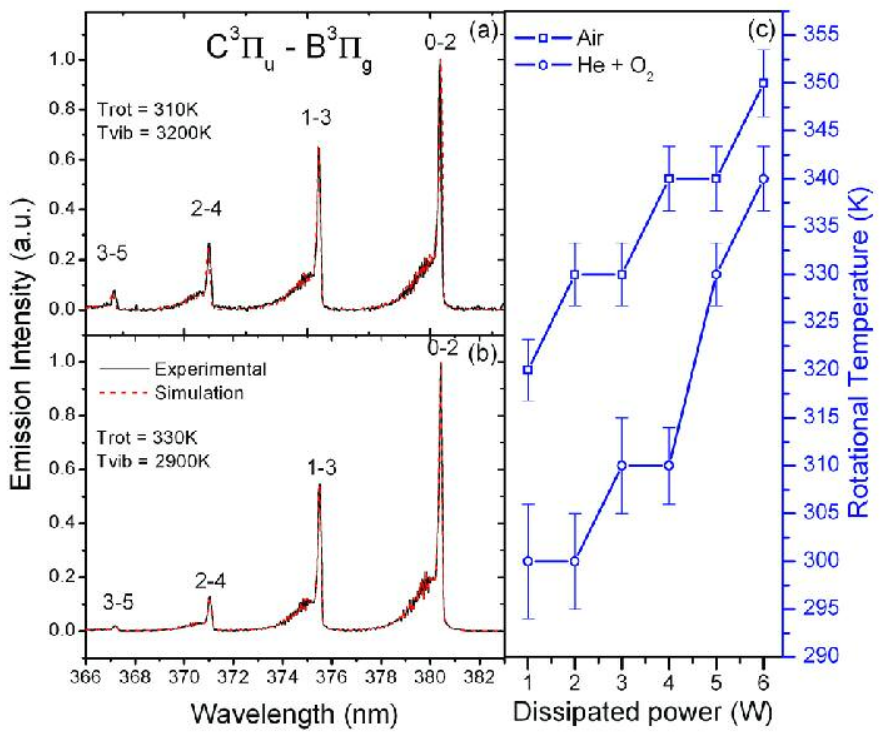

Figure 3: $\quad$ Experimental and simulated best-fit data of the second positive nitrogen emission band for (a) the $\mathrm{He}-\mathrm{O}_{2}$ plasma, and (b) the air plasma, both at $3 \mathrm{~W}$ of dissipated power, with the power dependence of $T_{\text {rot }}$ in (c). 


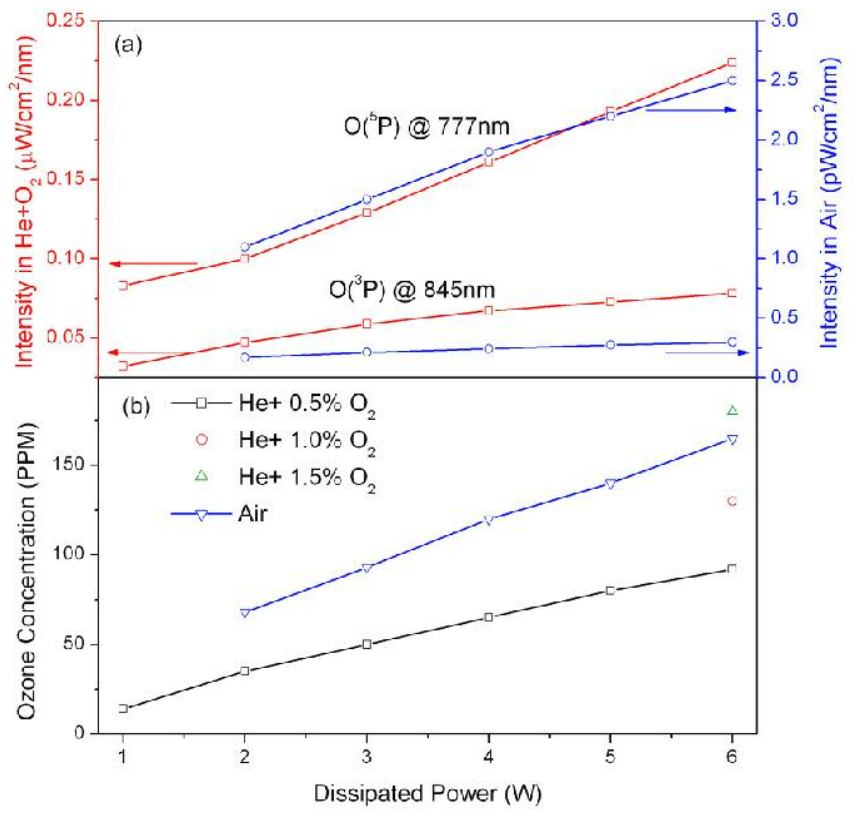

Figure 4: $\quad$ Dissipated power dependence of (a) the absolute emission intensity of $O\left({ }^{5} \mathrm{P}\right)$ at $777 \mathrm{~nm}$ and $\mathrm{O}\left({ }^{3} \mathrm{P}\right)$ at $845 \mathrm{~nm}$ and (b) ozone concentration for the air and the $\mathrm{He}-\mathrm{O}_{2}$ plasma. In the $\mathrm{He}-\mathrm{O}_{2}$ plasma, $\mathrm{O}_{2} / \mathrm{He}$ is (a) $0.5 \%$ and (b) $0.5,1.0$ and $1.5 \%$. 


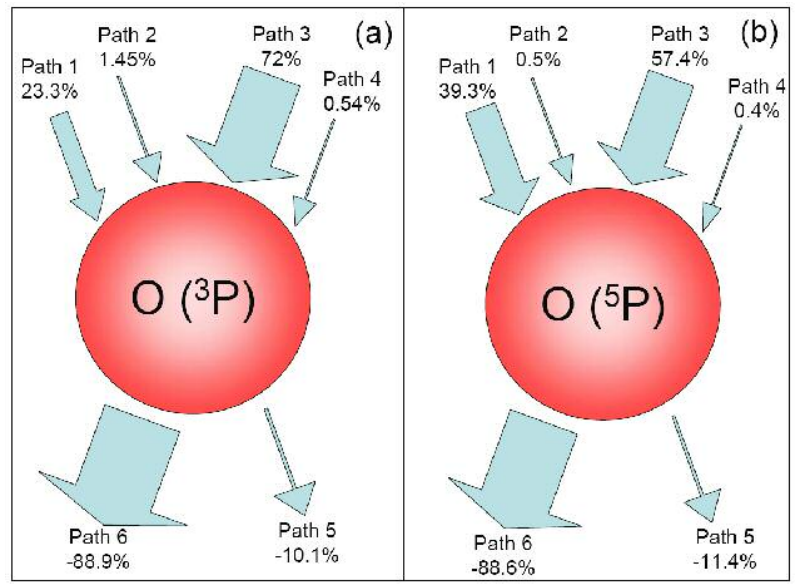

Figure 5: $\quad$ Schematic representation of the $\mathrm{He}-\mathrm{O}_{2}$ global model results showing key reaction pathways responsible for populating and depopulating $(\mathrm{a}) \mathrm{O}\left({ }^{3} \mathrm{P}\right)$ and (b) $\mathrm{O}\left({ }^{5} \mathrm{P}\right)$ at $6 \mathrm{~W}$ of dissipated power. Percentages indicate their relative contributions. 


\begin{tabular}{|c|c|c|c|}
\hline & Reaction & Rate $\left[\mathrm{cm}^{-3} \mathrm{~s}^{-1}\right]$ & Reference \\
\hline \multirow{2}{*}{ Path 1} & $e+O_{2} \rightarrow O\left(3 p^{3} P\right)+O+e$ & $1.51 \times 10^{-10} T_{e}^{0.5} \exp \left(-16.1 / T_{e}\right)$ & [26] \\
\hline & $e+\mathrm{O}_{2} \rightarrow O\left(3 p^{5} \mathrm{P}\right)+\mathrm{O}+e$ & $2.89 \times 10^{-10} T_{e}^{0.5} \exp \left(-15.9 / T_{e}\right)$ & {$[26]$} \\
\hline \multirow{2}{*}{ Path 2} & $e+O \rightarrow O\left(3 p^{3} P\right)+e$ & $3.23 \times 10^{-9} T_{e}^{-0.2} \exp \left(-10.98 / T_{e}\right)$ & [26] \\
\hline & $e+O \rightarrow O\left(3 p^{5} P\right)+e$ & $1.51 \times 10^{-9} T_{e}^{-0.45} \exp \left(-10.73 / T_{e}\right)$ & {$[26]$} \\
\hline \multirow{4}{*}{ Path 3} & $\mathrm{He}^{*}+\mathrm{O}_{2} \rightarrow \mathrm{O}+\mathrm{O}\left(3 p^{3} \mathrm{P}\right)+\mathrm{He}$ & \multirow{4}{*}{$1 \times 10^{-12}$} & \multirow{4}{*}[27]{} \\
\hline & $\mathrm{He}^{*}+\mathrm{O}_{2} \rightarrow \mathrm{O}+\mathrm{O}\left(3 p^{5} \mathrm{P}\right)+\mathrm{He}$ & & \\
\hline & $\mathrm{He}_{2}^{*}+\mathrm{O}_{2} \rightarrow \mathrm{O}+\mathrm{O}\left(3 p^{3} \mathrm{P}\right)+2 \mathrm{He}$ & & \\
\hline & $\mathrm{He}_{2}^{*}+\mathrm{O}_{2} \rightarrow \mathrm{O}+\mathrm{O}\left(3 p^{5} \mathrm{P}\right)+2 \mathrm{He}$ & & \\
\hline \multirow{6}{*}{ Path 4} & $O^{+}+O^{-} \rightarrow O\left(3 p^{3} P\right)+O$ & \multirow{6}{*}{$1 \times 10^{-9}$} & \multirow{6}{*}{$\begin{array}{l}\text { Estimated } \\
\text { from } \\
{[28][29]}\end{array}$} \\
\hline & $O^{+}+O^{-} \rightarrow O\left(3 p^{5} P\right)+O$ & & \\
\hline & $O_{2}^{+}+O^{-} \rightarrow O\left(3 p^{3} P\right)+O_{2}$ & & \\
\hline & $O_{2}^{+}+O^{-} \rightarrow O\left(3 p^{5} P\right)+O_{2}$ & & \\
\hline & $O^{+}+O_{2}^{-} \rightarrow O\left(3 p^{3} P\right)+O_{2}$ & & \\
\hline & $O^{+}+O_{2}^{-} \rightarrow O\left(3 p^{5} P\right)+O_{2}$ & & \\
\hline \multirow{2}{*}{ Path 5} & $O\left(3 p^{3} P\right) \rightarrow O\left(3 s^{3} S\right)+h v$ & $3.22 \times 10^{7}$ & [30] \\
\hline & $O\left(3 p^{5} P\right) \rightarrow O\left(3 s^{5} S\right)+h v$ & $3.69 \times 10^{7}$ & {$[30]$} \\
\hline \multirow{4}{*}{ Path 6} & $O\left(3 p^{3} P\right)+\mathrm{He} \rightarrow \mathrm{O}+\mathrm{He}$ & $7 \times 10^{-12}$ & {$[22]$} \\
\hline & $O\left(3 p^{5} \mathrm{P}\right)+\mathrm{He} \rightarrow \mathrm{O}+\mathrm{He}$ & $7 \times 10^{-12}$ & $\begin{array}{l}\text { Assumed } \\
\text { the same as } \\
\text { for } O\left({ }^{3} \mathrm{P}\right)\end{array}$ \\
\hline & $O\left(3 p^{3} P\right)+O_{2} \rightarrow O+O_{2}$ & $7.4 \times 10^{-10}$ & {$[26]$} \\
\hline & $O\left(3 p^{5} P\right)+O_{2} \rightarrow O+O_{2}$ & $1 \times 10^{-9}$ & {$[26]$} \\
\hline
\end{tabular}

